\title{
Defined Observation Result Target Coding System
}

National Cancer Institute

\section{Source}

National Cancer Institute. Defined Observation Result Target Coding System. NCI

Thesaurus. Code C93784.

The coding system to use for recording results for the associated activity or evaluation. 